\title{
A Buddhist Alternative
}

Abstract This chapter concludes with a summary of essential features of a Buddhist approach to thinking about the world, our role in it, and the type of political environments conducive to our higher nature. It notes that Buddhism has historically shaped a wide variety of societies in Asia and is adaptable to the Western world and to contemporary international challenges. Further, rather than being unscientific or otherworldly, Buddhist concepts are remarkably consistent with emerging findings in the natural and biological sciences.

Keywords Buddhist policy · Neuroplasticity - Quantum · Buddhism and science

\section{INTRODUCTION}

A Buddhist approach to IR provides an authentic and useful basis for comparison with Western models because of its distinct philosophical foundations: its ontology of radical interdependence, its ethics of responsibility for "others," and its assertion of the fundamental altruistic quality of a fully realized human nature. This approach, to use an overused term, is "revolutionary" in the sense that it challenges the deepest assumptions of mainstream Western social theory. Unlike most revolutions, this one is realized not on the streets so much as within our own minds; necessitating 
a fundamental reorientation in our perceptions, thoughts, emotions, and actions, including ultimately, political actions at the national and international level.

This short work outlines the political, economic, and international prescriptions that flow from this different mindset and that, in turn, support the mental and material development of individuals in reaching their fuller potential. Further, it provides two examples of attempts to put these ideas into practice: one historical and one contemporary.

\section{IMPLICATIONS FOR TODAY'S CHALLENGES}

A Buddhist social theory necessarily begins with the doctrine of radical interdependence, which underscores an individual's responsibilities for others, not just the promotion of individual choice and self-interest. Buddha's social formula gives greater emphasis to the duty of care we owe each other and our natural and social environments. This concern is reflected at a minimum in the principles of non-harm, nonaggression, and equality and ideally grows into an ethic of universal compassion. At a national policy level, this political orientation might translate into the promotion of democracy with an equal emphasis on individual freedoms and social and environmental responsibility, for example. Buddhist politics counsels that political systems must consciously weigh the balance between the independence and interdependence of individuals in society, and Buddhism's assertion of radical interdependence tells us our current fetish of radical individualism does not reflect reality. Politics, in Buddhism, is not divorced from ethics and it recommends an emphasis on civic virtues. Politics should reflect society's aspirational values, especially the value of equality in terms of political access and avenues for participation and equality of justice under law. Beyond impartiality, politics and policy must also reflect ethical principles such as honesty and transparency, generosity, non-harm, forbearance, empathy, and a willingness to compromise. National economic policies in turn should focus on reducing the suffering of poverty by providing a strong social safety net and encouraging full employment. Economic policy must also protect workers and the environment from exploitation.

At the international level, a Buddhist approach might include initiatives that encourage a deeper recognition of our common humanity and equality over particularism and nationalism. To illustrate a Buddhist approach to one contemporary global challenge, the world might learn 
from humble Bhutan's example in addressing the issue of environmentally sustainable economic growth. Because of its Buddhist conviction that all reality is interdependent and that our ethical responsibilities apply not just to other individuals but to "all sentient beings" in this and future lives, Bhutan has adopted strict environmental policies that govern its economic development despite its status as low-income country. This commitment is embodied in Bhutan's Constitution, the first in the world to require environmental sustainability and one that mandates that 60 percent or more of all land remain forested in perpetuity (Constitution of the Kingdom of Bhutan, Art. 5.3). In practice, Bhutan keeps 70 percent of its land in its pristine state and is a carbon negative country while maintaining an enviable growth rate. Notably, as discussed in Chapter 3, sustainability is an integral and natural dimension of Buddhist economics through its emphasis on contentment, moderation, concern for others (even future generations), and the importance of living in harmony with nature. This approach differs from the prevailing liberal economic approach where notions of sustainability are awkwardly bolted onto, and in tension with, a maximization model. In her recent work on Buddhist economics, Clair Brown explains that Buddhist economics requires "strong sustainability" whereas free market economics pursues "weak sustainability" (Brown 2017). The former connotes that physical limits on natural capital exist and critical ecosystems must be preserved; and the later means that humans can freely trade off different inputs into the production process (Brown 2017 at pp. 64-65).

Buddhism's instrumental view of politics and its basic pragmatism and flexibility make it amendable to many different and culturally appropriate ways for putting its basic social principles into practice. In the East, Buddhism has shaped societies as diverse as India and China, and it is reasonable to assume that its social teachings can be integrated into Western social theory and practice too.

In a Buddhist perspective, these "obligations" to care for others broadly, both within and across societies, are not an imposition on, or at odds with individual freedom or particularistic identities, but an opportunity for individuals to find happiness and fulfillment that transcend the pursuit of personal desires or in-group advantage and gain real freedom from excessive self or national concern. Moreover, this alternative view of social reality is, for Buddhists, consistent with how all things actually exist (interdependently) and consistent with our abiding human nature, 
which is, at its core, altruistic. From a Buddhist perspective, the separation, insecurity, and fear that constitutes the starting point of Western social thinking, is based in ignorance, not truth. Because this deluded way of looking at ourselves and the world is pervasive, however, we must work the problem, "free our minds" as it were. Buddhist's call this exertion on behalf of ourselves and others the "perfection of effort." With effort, everything comes.

Lest we think these ideas are mere fantasy, we can consider past and present efforts to put these ideas into practice, however imperfectly, in the ancient empire of Aśoka and in modern Bhutan. These examples are not presented as earthly Shangri-las, but they each reflect an effort to pursue policies of nonviolence, nonbelligerence, tolerance, equality, generosity, good governance in supporting individuals' holistic development, social responsibility, mutual benefit, and rule of law.

Although a Buddhist perspective is different from those that predominate in the West, it is not, fundamentally, an alien one. Buddhism, while ancient and "oriental" in its origins, at its core makes universalistic, not particularistic, assertions - suffering, for example, is a human condition as is the potential for liberation. And, as noted earlier in the work, many Buddhist ideas accord with those of the Western Enlightenment and with the principles of modern welfare state democracies, liberal internationalism, international society, and cosmopolitan ethics. Having introduced this Eastern model to Western IR, and aware of their many common interests, this author encourages those concerned with a politics of human liberation to continue the dialogue.

\section{BudDHISM AND SCIENCE ${ }^{\mathrm{I}}$}

This work concludes by considering a profound doubt that surrounds a Buddhist prescription for the social world: is Buddhism, as a spiritual tradition, "unscientific"? Specifically, the concern centers on two key principles of Buddhism that are the foundation of its social theory articulated in Chapter 2: first, the notion of the radical interdependence of reality and, second, the assertion of an ultimately altruistic and perfectible human nature. Although appealing ideas, even scholars sympathetic to integrating Eastern philosophy with international relations, such as Acharya, worry that these concepts might appear unrealistic, otherworldly, spiritual aspirations and therefore outside of the scientific study of international relations. 
To understand why Buddhist assertions might be viewed as outside the scientific mainstream requires an appreciation for the relationship of the natural sciences to Western social theory (including mainstream IR theory) historically. Mainstream international relations theory, like most Western political theory, paralleled and conformed with the Enlightenment's classical scientific tenets regarding the physical world: material realism, objectivism, and localized physical causation. Social thinkers intuitively adopted these ontological and empirical assumptions and offered theories of human nature and social possibilities based on them. The link between the social sciences and the natural sciences was primarily metaphysical, epistemic, and methodological; that is, social theorists adopted the Cartesian separation of subject from object, self from other, and mind from matter; the positivist assumption of the possibility of discovering law-like generalizations about social behavior, much like scientists seeking to establish facts about the natural world; and the preference for third-party, replicable empiricism methodologically. The predominant political and economic conclusion flowing from a classical scientific foundation is that insecurity and conflict naturally arise in groups of inherently real, independent, and self-interested actors. Thus, the benefits of society are unlikely without a fear-based social contract, a "Smithian" economic system that maximizes the benefits possible from humans' propensity for incessant competition, and by extension, the pursuit of a balance of power among self-interested states acting in an anarchic environment. Buddhist social theory, based on the ontology of radical interdependence, refutes this approach.

The Buddhist assertion that human nature is fundamentally altruistic and perfectible through mind training also contradicts traditional scientific notions in biology and physiology. According to the historically dominant scientific view, individuals have been hardwired over thousands of millennia to be self-interested, competitive, even aggressive. Social institutions can, at best, modulate and channel these propensities. For classical material science, the notion of molding one's mind through right view (intention), mindfulness (attentiveness), concentration, and meditation to reorient our thoughts, feelings, and actions in a more altruistic and cooperative direction and claiming that our reality is impermanent and wholly interdependent as Buddhism does, are untenable assertions. Buddhism, in contrast to materialist science, asserts a causal power for a nonphysical mind and it treats material realism only as functional appearance, not ultimate truth. 
During the past century, however, Western science itself has begun to question the precepts of the dominant physical and physiological paradigm and, in so doing, encouraged those of us in social disciplines to reconsider our assumptions about reality, human nature, and the possibilities for human behavior and social organization. Emerging findings in physical and life sciences, much like Buddhism, suggest that reality may be much more interdependent than we previously appreciated and that our human nature and our ability to shape our thoughts and emotions in more positive directions are greater than once realized.

To appreciate this convergence between Buddhist philosophy and contemporary Western physical and life sciences requires a summary of recent findings in quantum physics and neuroscience, which suggest that our reality is interdependent and indeterminate and that the brain regenerates and reprograms itself throughout life in response to environmental challenges and the mental force of intention and attention. These recent scientific discoveries may be pointing to a different scientific picture of reality and human nature, one that is consistent with Buddhist philosophy. Recent scientific investigations, while speaking an entirely different language than Buddhism, may be saying much the same thing about the nature of our reality and our mental capacity. The quantum revolution in the physical world and discoveries in the life sciences that address directly the malleability of the structure and function of the brain (the seat of human nature for modern science) are challenging the ontological and epistemological foundations of materialism, objectivism, and atomism and, by extension, undermining the presumed unchangeable self-interested behavior that flows from these classical science foundations.

New findings in contemporary neuroscience and physical science suggest that human nature may be more variable and flexible and more susceptible to our mental training than once imagined. From this perspective, although we inherit certain morphology and traits, these traits, and even the morphology, may be more malleable than we thought. We may be able to change our thoughts, emotions, and the resulting behavior through repeated mental effort. These ideas are relatively new, partial, and highly contested, but worth our consideration. To better appreciate these new scientific discoveries and how they are comparable to Buddhist philosophy, below I provide a very brief outline of quantum science and neuroplasticity. 


\section{The Quantum Revolution}

A formal discussion of quantum hypotheses (they are numerous, varied, and vigorously debated) is outside the purview of this book and well beyond the author's capabilities. The basic findings of quantum physics and a consideration of their possible behavioral and ethical implications are reachable and relevant to this discussion, however.

Quantum theory challenges the ontological and epistemological foundations of the classical scientific worldview that formed the implicit philosophical foundation for modern Western political thought, including mainstream IR. Recall that under the classical view, reality consists of material objects forever separated from the immaterial mind, and objects exist independently of the subjects that observe them. Science concerns itself with discovering the cause and effect of natural laws that operate in the physical world. Causation is mechanical, determinable, and localized. The mind, therefore, as a nonphysical entity, is no longer relevant or real from a scientific perspective.

Quantum physics describes a very different world. When scientists analyzed atomic and subatomic particles, the ultimate building blocks of the material world, they discovered that they do not conform to classical suppositions. In the subatomic world, particles have no definite position or values, no fixed or material properties, until they are measured. Reality does not exist "out there" independent of human choice and our observation of it. Instead, scientists found that subatomic particles exist-or can best be represented as existing - as an immaterial wave of potential realities (probabilities) that only become fixed with material properties when the subject observes them (the so-called collapse of the wave function or the quantum leap). Before the observation, the quantum system has a range of possibilities; afterward it has a single actuality.

This finding (upheld in countless experiments), that there is no fixed reality until an observer asks a specific question of nature and observes the answer nature provides, overturns the separation of subject from object and mind from matter that have been the essence of the classical material world-view since Francis Bacon. In quantum dynamics, observer and observed are now understood as part of one system. They only emerge as independent entities through the process of observation and measurement. There are no objects independent of our conceptual designations. Likewise, epistemology is changed by the quantum revolution. Rather than certainty waiting to be discovered, the physical world is uncertain 
(existing as probabilities) and indeterminate. Physics then is about determining what is known or knowable, not about what "is." There is no one true and complete description of the way the world is. Physical theory thus underwent a tectonic shift, from a theory about physical reality to a theory about our knowledge, from ontology to epistemology. Science is what we know, and what we know is only what our observations tell us. As Werner Heisenberg phrased it, "What we observe is not nature itself but nature exposed to our method of questioning" (Heisenberg 1962 at p. 58).

Classical notions of mechanical, localized causation are also altered by quantum science. Locality means that physical reality in one place cannot be affected instantaneously by an action in some faraway place. That is, separation implies physical independence absent a demonstrable physical and temporal link (contact) between objects. Quantum theory violates locality, at least in certain circumstances. Quantum "nonlocality" means that wave functions have effects on other wave functions in the absence of any apparent, material, localized causal connection. Particles are "entangled." Scientists discovered that when one wave function changes as the result of measurement, the appropriate description of the other wave function under examination instantaneously changes as well, "and that 'other' can be as far away as one would like, from the other side of the laboratory to the other side of the galaxy" (Schwartz and Begley 2002 at p. 347). Particles are not atomistic and do not behave as distinct objects, but operate as parts of a seamlessly interconnected whole that absorbs their individual identities (Albert 1992). Quantum science implies a radical interdependence among particles and a universe that is more closely enmeshed than the classical worldview. In this realm, nothing can be defined except in relation to another thing.

The possible ontological implications of quantum physics are truly revolutionary. First, subject and object are reconnected in creating our reality. Second, since everything is interdependent, nothing can be selfdefining and exist inherently. Finally, in the quantum universe, causation ultimately is holistic, not mechanistic.

What then of the world as we think it exists, as tangible objects independent of our minds and, absent a local link, independent of each other? Quantum physics explains that, when one moves from the molecular level to larger objects, quantum states normally "decohere" and appear to us as classical matter, even though, ultimately, they do not exist this way. Whenever particles interact in their environment, in a lab or in nature, they are 
in effect measuring each other, inducing decoherence (they are no longer able to remain "entangled"). This decoherence explains why, in everyday life, we see only material objects, not wave functions, and these objects appear to conform to classical mechanics. Classical science can still study observables, and classical physical theories explain more-or-less accurately larger observed phenomena.

Quantum ontology forces us to distinguish between the way things appear and the way things exist, between working "truth" and reality, or, in Buddhist terms, between conventional and ultimate truth. Quantum discoveries suggest that indeterminacy is the only absolute truth, that is, everything lacks an inherent, fixed existence, or, to phrase it another way, all things are interdependent. The usefulness of classical physics for interpreting the action of objects larger than atomic or subatomic particles should not be confused with the ultimate nature of these objects. The quantum view of matter and mind as dependent on each other refutes metaphysical realism and is generally more consistent with the Buddhist notion of the "two truths"-conventional and ultimate-discussed in Chapter 2.

Finally, quantum metaphysics also avoids the two extremes of materialism (all is matter) and idealism (all is mind). In quantum metaphysics, neither mind nor matter take precedence as inherently real; together they give objects a defined nature. Object and subject are, to use an earlier Buddhist term, "dependent co-arising" (pratitya-samutpada).

A basic tenet of classical science is reductionism: larger objects can be reduced to smaller ones in determining fundamental physical principles. Further, because physics is the science that explores the elemental constituents of reality, it is foundational to other sciences and, implicitly, social depictions of reality as well. Ironically, in pursuing reductionism to its limits, physicists discovered a world fundamentally different from classical representations, and their findings challenge other scientific fields, and I would argue even social scientific disciplines, to accommodate this new conception of reality.

\section{Reconsidering Brain, Mind, and Human "Nature"}

In addition to revolutionary changes in the physical sciences, the life sciences too have made remarkable new discoveries that challenge our thinking about human nature as irreversibly self-interested and expand the possibilities for considering our cooperative potential and corresponding 
social arrangements. Until relatively recently, the prevailing view in neuroscience was that the brain contained all its neurons at birth, and the number and circuitry of these neurons were set within the first few years of life. Scientists believed that the only lifelong brain changes were minor alterations in synaptic (interneuronal) connections and accelerating cell death with aging. Social scientists in the Western tradition assumed that this relatively fixed brain was, by nature, first and always primarily self-interested and self-serving.

In the 1990s, however, neuroscientists discovered that the brain continues to generate new neurons throughout life (neurogenesis) and that new and existing neurons undergo structural and functional changes in their circuitry in response to their environments, by training and experience (neuroplasticity). Contrary to what was once believed, the brain is highly dynamic (Eriksson et al. 1998). When referring to changes in the brain, it is important to distinguish between gross morphology and cellular structure and function. The overall structure and pattern of brain development is under genetic control and does not change markedly. But our 35,000 genes are not up to the job of prescribing the wiring for the brain's 100 trillion or more synapses. These connections are shaped by our ongoing experiences. It is at this cellular level that the brain is remarkably plastic.

Neuroplasticity refers to altering connections in the brain, the strengthening, withering, or rerouting of synaptic connections. Neuroplasticity is more than mere learning or storing a memory. The brain is far more flexible than that. It can make wholesale topographical reorganizations throughout life (Elbert et al. 1995). For example, experiments demonstrate that some brain areas that were thought to be "hardwired" for one function can in response to injury and adaptive effort, take on a totally different function, what scientists call cross-modal functional plasticity. Altering connections in the brain in a way that strengthens the efficacy of a neuronal circuit over the long term is the essence of neuroplasticity.

How does the brain accomplish these adaptive feats? Various new technologies are giving us a glimpse of this process. These new technologies are illuminating the neural correlates for specific adaptations wrought through repeated experiences. These technologies can also show us the brain areas and patterns of electrochemical activation associated with a mental process. In discovering and observing the link between brain circuitry and mental states, some scientists are also suggesting that the causal connection between brain and mind works in both directions 
(Lutz et al. 2004). Specifically, they offer intriguing new evidence to suggest that the processes of brain wiring and rewiring may be shaped by mental (nonphysical) events. This work reveals that it is not just experience that molds the brain. Rather, changes in brain circuitry are generated only when behavior is specifically attended to. Attention (mindfulness), is required for use-dependent brain changes. In fact, imagined physical movements, if repeated with concentration, can produce the same synaptic changes as actual repetitive body movements (Schwartz and Begley 2002; Slotnick 2004). Similarly, mental imagery correlates with the activation of the same brain areas as those associated with the actual perception of the imagined object. In short, mental force appears to express itself through the brain, but it is not reducible to the brain.

Some neuroscientists began looking at the brain activity ("brain state") and cognitive and neural characteristics ("brain traits") of meditators to better understand the immediate and long-term effects of focused awareness. These studies produced preliminary evidence for the possibility that mental training may alter brain activity, shape the physical brain, and affect human behavior. Early work by Richard Davidson, Antoine Lutz, and others found that sustained thoughts activated certain neuronal pathways in the brain associated with the regulation of positive affect (like compassion), reduced negative thoughts and feelings such as anxiety and depression, and subdued self-referential thoughts (See Davidson et al. 2003; Pollard 2003; Lutz et al. 2004). These early studies lent support to the notion that a willful refocusing of mental awareness could bring about important changes in brain activity and structure (Brefczynski-Lewis et al. 2007; Lazar et al. 2005).

These initial investigations have led to hundreds of recent studies on the impact of various forms of mindfulness and meditation on brain functioning and morphology. Two "metastudies" (studies of studies) reviewed these experiments looking for methodological reliable and comparable results. One of these metastudies concluded "that meditation appears to be reliably associated with altered anatomical structure in several brain regions" (Fox et al. 2014 at p. 69). The brains of meditators were altered in eight brain regions including areas related to meta awareness (our ability to watch our own minds), body awareness, memory consolidation and reconsolidation, self and emotional regulation, and infra and interhemispheric communication (Fox et al. 2014; see also Afonso et al. 2020 ). The second metastudy concluded that meditation produces positive effects on cognitive and emotional processes (Sedlmeier et al. 2012). 
Several individual studies raise intriguing possibilities. For example, one study found that meditators, unlike control subjects, had reduced activity in "self-referential processing," i.e., mind wandering, which appears to be our default mechanism and is often correlated with unhappiness (Brewer et al. 2011). Another study found that meditation increased compassionate responses to suffering, even in the face of social pressures to avoid so doing (Condon et al. 2013).

As noted, these changes in brain function and form do not occur without sustained and repeated effort, however. Absent focused attention, the brain will produce predictable patterns of brain activity, that is, our default mode of thinking. Through choice and willful attention, however, it appears that an alternative synaptic path may be activated and perpetuated. The idea that immaterial forces such as intention and attention could shape the brain's function and form runs counter to classical materialist science. Working in the materialist tradition, most scientists, including almost all neuroscientists, have assumed that mental processes are inefficacious byproducts of purely physical brain processes. To the extent that one can recognize the mind at all, brain to mind is a one-way street. All our thoughts and actions are reducible to impersonal, microscopic, physical processes. Nothing that is nonphysical, such as the mind, consciousness, or will, can even exist in the sense of being a measurable, real entity much less shape physical outcomes.

This classical approach has been unable to explain how brain activity gives rise to consciousness (subjectively felt mental states), however, and what role consciousness might play in the brain's workings. Why, if exclusively local physical processes in the brain control us, do we possess a stream of conscious thoughts capable of understanding large-scale phenomena? After 350 years of classical material science and more than half a century of neuroscience, materialist approaches have done a good job of linking structure and function in the brain, but have made no progress in explaining consciousness, something we all experience most all the time. In the materialist paradigm, accounting for consciousness is the "hard problem," and because consciousness cannot be effectively explained by reference to material forces, for most scientists in the classical material tradition, consciousness either is not a legitimate area of inquiry or, if it is, they have promised, since the eighteenth century, that a materialist answer to the hard problem of consciousness is only a matter of time (Araujo 2012). 
The idea that the process of brain wiring and rewiring is shaped by immaterial mental events may confound classical materialist science (which either denies mind or separates mind from matter), but it is not inconsistent with quantum science (which sees mind and matter as inextricably entwined). Recall that in the quantum world, the subject determines which of many possible realities becomes actualized through its intention and attention. Quantum theory reunites consciousness with the causal structure of nature, joining subjective experience and objective outcomes. Thus, quantum theory creates a "causal opening for the mind," a point of entry by which mind could alter the functioning and shape the physical structure of the brain.

Is there evidence for the existence of a "quantum brain" or "quantum consciousness?" At this point we do not know, and it remains to be seen where, if anywhere, there exists a demonstrable locus for quantum effects in the brain. Because the environment for sustained quantum effects to operate in the brain has not been sufficiently established, traditional neuroscience argues that brain functions can, indeed must, be understood as the interactions of neurons operating under classical physical principles. Still, we know that quantum physics operates sub-atomically everywhere, and we know that mechanical explanations of neuronal function cannot account for the processing speed of the human brain. Furthermore, there is evidence that sustained thought alters brain states and traits; we just do not know how or precisely where this occurs. Quantum theory raises the following question to material neuroscience: How can the mind and consciousness be reduced to the function of atoms within the brain if we know that ultimately these atoms have no fixed or non-probabilistic existence outside of subjective mental events? If atoms derive their properties from interaction with consciousness [in quantum], how can consciousness depend only on those same atoms? (Schwartz and Begley 2002).

In truth, at this moment, both materialism and quantum approaches toward mind are meta-physical assertions awaiting more evidence, an epistemic exercise. Science should be about epistemic pursuits, not metaphysical closure, so let us keep an open mind. Asserting that a nonmaterial force (thought) can shape a material object such as the brain, as quantum theory does, is no more speculative than asserting a material basis for nonmaterial consciousness, which is the prevailing materialist neuroscience view. With the advent of quantum theory, the nature of matter has become as problematic as the nature of mind. 


\section{Implications of New Scientific Discoveries for Social Theory}

I only report on this ongoing scientific debate to consider its possible implications for the discussion at hand. As noted, some social scientists wonder "Are Buddhist ideas harmonious with science?" The answer, I suggest, is "yes," they are remarkably consistent with the latest findings in the physical and biological sciences, not "otherworldly."

Coming back to the focus of this discussion (and firmer footing for the author), the quantum explanations for brain plasticity and a causal role for mind carry potentially important behavioral and moral consequences for social thought and action coming from the world of science (Wendt 2015). If true, they would imply that, although we are endowed with a given brain morphology and basic circuitry, not all aspects of our responses are passively determined by neurobiological mechanisms. Instead, our volitional choices moment to moment to attend to one bit of environmental stimulation over another and to form, through our intention and attention (the driving force of karma, for Buddhists), one thought pattern rather than another, can sculpt our brain and make us who we are.

Cartesian science divorced morality from the material world by separating it from the mind. Physical things just are; they are not right or wrong. Our mind is just brain, and our brain is just an amalgam of determined electrochemical processes. This view of mind as reducible to classical physical forces is inimical to both moral responsibility and personal freedom. But if the mind is not fully controlled by deterministic physical phenomena and can shape thought patterns, emotions, and even physical reality (such as the brain) by the choices it makes and the causal efficacy of will, then mental phenomena are morally responsible. In this view, it is the interplay between the electrical and chemical processes and the role of consciousness that determines both our thoughts and physical correlates in brain circuitry.

What then of human nature and the range of possible and ethical human behavior and social organization in view of the quantum revolution and recent neuroscientific findings? Evidence for the power of the mind would carry profound implications for our understanding of "human nature" and responsible social behavior, too. Some of the consequences for social theory are clear. First, it would that mean whatever we decide is our inherent nature (selfish, altruistic, or some combination thereof), our nature may not be fixed and fully determined and it changes, 
in part through the mental decisions (actions) we make throughout life. If this assertion is true, then it may be possible to alter the balance in the mind between selfishness and empathy, between fear and compassion, and between anger and patience through conscious mental effort.

The implications of this proposition for our moral responsibility are truly sobering: ultimately, our brain is as selfish or as altruistic as our mind trains it to be, and our behaviors and actions, including our collective actions are, ultimately, our responsibility. Furthermore, if society, polity, economy, and even international relations in theory and practice should align themselves with our best understanding of physical reality and human nature and potential, then we would need to look anew at our assumptions about human "nature" and the possibilities for our social constructs.

\section{CONCLUSION}

Buddhism presents us with a wholly different set of assumptions about ourselves and our relationship to others and all things. It recommends political and economic institutions and policies that comport with an ultimate ontological truth of radical interdependence and the ethical responsibilities a trainable mind entail. Einstein reminds us: "no problem can be solved by the same consciousness that created it." A Buddhist approach to today's international challenges represents at its deepest level an ancient, yet innovative, way of thinking about our social and natural worlds, our ethical responsibilities, and "ourselves."

\section{Note}

1. Portions of this discussion are taken from the author's earlier work, Tantric State: A Buddhist Approach to Democracy and Development in Bhutan, New York: Oxford University Press, 2019.

\section{REFERENCES}

Afonso, R.F., I. Kraft, M.A. Aratanha, and E.H. Kozasa. 2020. Neural Correlates of Meditation: A Review of Functional MRI Studies. Frontiers in Bioscience 12: 92-115.

Albert, David. 1992. Quantum Mechanics and Experience. Cambridge, MA: Harvard University Press. 
Araujo, S. 2012. Materialism's Eternal Return: Recurrent Patterns of Materialist Explanations of Mental Phenomena. In Exploring Frontiers of Mind-Brain Relationship, ed. Alexander Moreira-Almeida and Franklin Santana Santos, 3-15. New York: Springer.

Brefczynski-Lewis, J.A., A. Lutz, H.S. Schafer, and R.B. Davidson. 2007. Neural Correlates of Attention Expertise in Long-Term Meditation Practitioners. Proceedings of the National Academies of Sciences USA 104 (207): 11483-11488.

Brewer, Judson, Patrick Worhunsky, Jeremy Gray, Yi-Yuan Tang, Jochen Weber, and Hedy Kober. 2011. Meditation Experience Is Associated with Differences in Default Mode Network Activity and Connectivity. Psychological and Cognitive Sciences 108 (50): 20254-20259.

Brown, Clair. 2017. Buddhist Economics: An Enlightened Approach to the Dismal Science. New York: Bloomsbury.

Condon, P., G. Desbordes, A.M. Miller, R. Smith, and J.W. Schooler. 2013. Meditation Increases Compassionate Responses to Suffering. Psychological Science 24 (10): 2125-2127.

Constitution of the Kingdom of Bhutan, July 18, 2008, Thimphu, Bhutan.

Davidson, R.J., J. Kabat-Zinn, J. Schumacher, M. Rosenkrantz, D. Muller, S.F. Santorelli, F. Urbanowski, A. Harrington, K. Bonus, and J.F. Sheridan. 2003. Alterations in Brain and Immune Function Produced by Mindfulness Meditation. Psychosomatic Medicine 65: 564-570.

Elbert, T., C. Pantene, C. Weinbruch, B. Rockstroh, and E. Taub. 1995. Increased Cortical: Representation of the Fingers of the Left Hand in String Players. Science 270 (5234): 305-307.

Eriksson, P., E. Perfilieva, T. Bjork-Eriksson, A. Alborn, C. Nordborg, D. Peterson, and F. Gage. 1998. Neurogenesis in the Adult Human Hippocampus. Nature Medicine 4: 1313-1317.

Fox, K., C.R.S. Nijeboer, M.L. Dixon, J.L. Floman, M. Ellamil, S.P. Rumak, P. Sedlmeier, and K. Christoff. 2014. Is Meditation Associated with Altered Brain Structure? A Scientific Review and Meta-Analysis of Morphometric Neuroimaging in Meditation Practitioners. Neuroscience and Biobehavioral Reviews 43: 48-73.

Heisenberg, W. 1962. Physics and Philosophy: The Revolution in Modern Science. New York: Harper and Row.

Lazar, S., W.C.E. Kerr, R.H. Wasserman, J.R. Grey, D.N. Greve, M.T. Treadway, M. McGarvey, B.T. Quinn, J.A. Dusek, H. Benson, S.L. Rauch, C.I. Moore, and B. Fishl. 2005. Meditation Experience Is Associated with Increased Cortical Thickness. NeuroReport 16: 1893-1897.

Lutz, A., L.L. Greischar, N.B. Rawlings, M. Richard, and R.J. Davidson. 2004. Long-Term Meditators Self-Induce High-Amplitude Gamma Synchrony 
During Mental Practice. Neuroscience, National Academy of Science of the USA 101 (46): 16363-16373.

Pollard, I. 2003. From Happiness to Depression. Today's Life Sciences 15: 22-26. Schwartz, J., and S. Begley. 2002. The Mind and the Brain: Neuroplasticity and the Power of Mental Force. New York: Regan Books.

Sedlmeier, P., J. Eberth, M. Schwartz, D. Zimmerman, F. Haarig, S. Jaeger, and S. Kunze. 2012. The Psychological Effects of Meditation: A Meta-Analysis. Psychological Bulletin 138 (6): 1139-1171.

Slotnick, S.D. 2004. Visual Memory and Visceral Perception Recruit Common Neural Substrates. Behavior and Cognitive Neuroscience Review 3: 207-221.

Wendt, Alexander. 2015. Quantum Mind and Social Science: Unifying Physical and Social Ontology. Cambridge: Cambridge University Press.

Open Access This chapter is licensed under the terms of the Creative Commons Attribution 4.0 International License (http://creativecommons.org/licenses/ by $/ 4.0 /$ ), which permits use, sharing, adaptation, distribution and reproduction in any medium or format, as long as you give appropriate credit to the original author(s) and the source, provide a link to the Creative Commons license and indicate if changes were made.

The images or other third party material in this chapter are included in the chapter's Creative Commons license, unless indicated otherwise in a credit line to the material. If material is not included in the chapter's Creative Commons license and your intended use is not permitted by statutory regulation or exceeds the permitted use, you will need to obtain permission directly from the copyright holder.

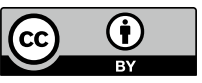

